Supplement of Atmos. Chem. Phys., 19, 1-14, 2019

https://doi.org/10.5194/acp-19-1-2019-supplement

(C) Author(s) 2019. This work is distributed under

the Creative Commons Attribution 4.0 License.

(c) (1)

\section{Atmospheric \\ Chemistry \\ and Physics}

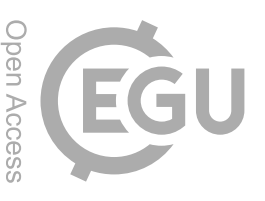

Supplement of

\title{
The significant contribution of HONO to secondary pollutants during a severe winter pollution event in southern China
}

Xiao Fu et al.

Correspondence to: Tao Wang (tao.wang @ polyu.edu.hk)

The copyright of individual parts of the supplement might differ from the CC BY 4.0 License. 
Table S1. Performance statistics of meteorological variables for the innermost domain

\begin{tabular}{|c|c|c|c|c|}
\hline Variable & $\mathrm{T} 2{ }^{\mathrm{c}}\left({ }^{\circ} \mathrm{C}\right)$ & $\mathrm{H} 2^{\mathrm{c}}(\mathrm{g} / \mathrm{kg})$ & $\mathrm{WS} 10^{\mathrm{c}}\left(\mathrm{m} \mathrm{s}^{-1}\right)$ & $\mathrm{WD} 10^{\mathrm{c}}\left(^{\circ}\right)$ \\
\hline Mean OBS ${ }^{a, b}$ & 20.8 & 13.3 & 2.4 & 229.2 \\
\hline Mean SIM ${ }^{\mathrm{b}}$ & 20.4 & 12.2 & 2.1 & 232.5 \\
\hline $\mathrm{MB}^{\mathrm{b}}$ & -0.4 & -1.1 & -0.2 & 3.3 \\
\hline $\operatorname{NMB}^{\mathrm{b}}(\%)$ & -2.0 & -8.1 & -8.9 & 1.4 \\
\hline $\operatorname{NME}^{\mathrm{b}}(\%)$ & 5.1 & 11.2 & 41.7 & 24.6 \\
\hline
\end{tabular}

a The observation data was obtained from the National Climatic Data Center (NCDC) (https://www7.ncdc.noaa.gov/CDO/cdo ).

${ }^{\mathrm{b}}$ Mean OBS: average observed values; Mean SIM: average simulated values; MB: bias; NMB: normalized mean bias; NME: normalized mean error.

${ }^{\mathrm{c}} \mathrm{T} 2$ : temperature at 2 meter; $\mathrm{H} 2$ : specific humidity at 2 meter; WS10: wind speed at 10 meter; WD10: wind direction at 10 meter.
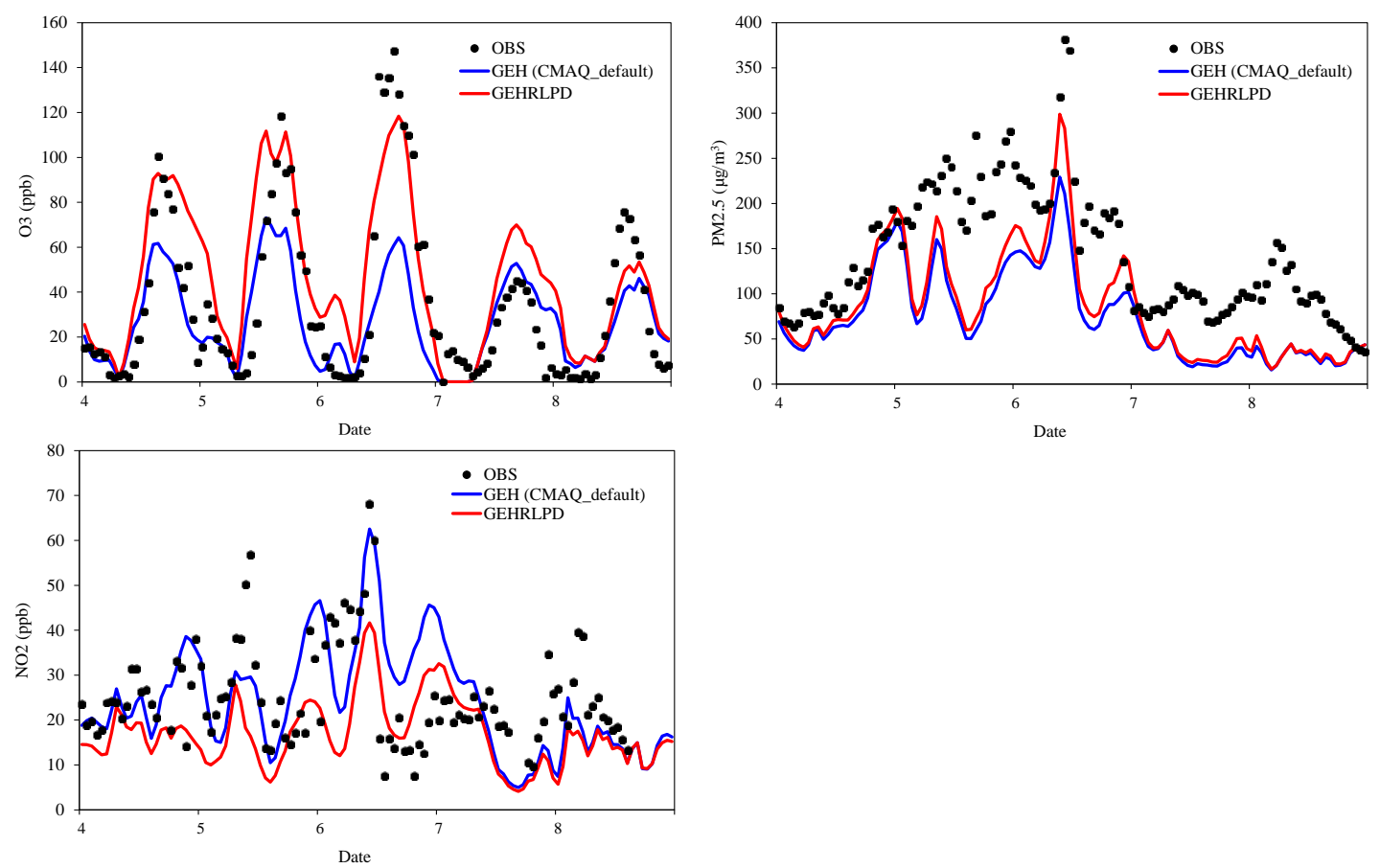

Fig. S1. Observed and simulated $\mathrm{O}_{3}, \mathrm{PM}_{2.5}$ and $\mathrm{NO}_{2}$ concentrations by the default and revised CMAQ model at Heshan site 

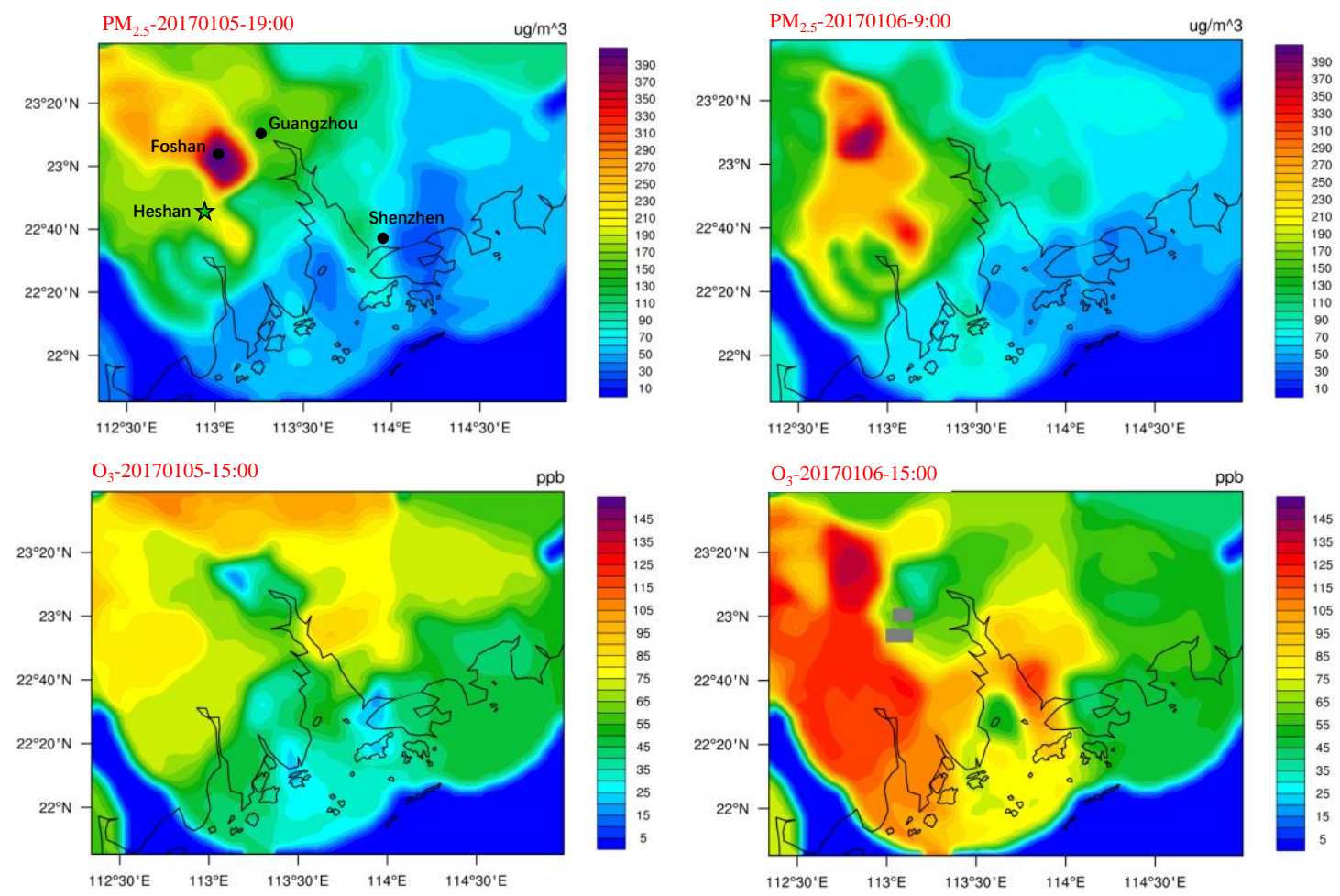

Fig. S2. Spatial distribution of observed $\mathrm{PM}_{2.5}$ (19:00 on 5 January and 9:00 on 6 January) and $\mathrm{O}_{3}(15: 00$ on 5 and 6 January) concentrations
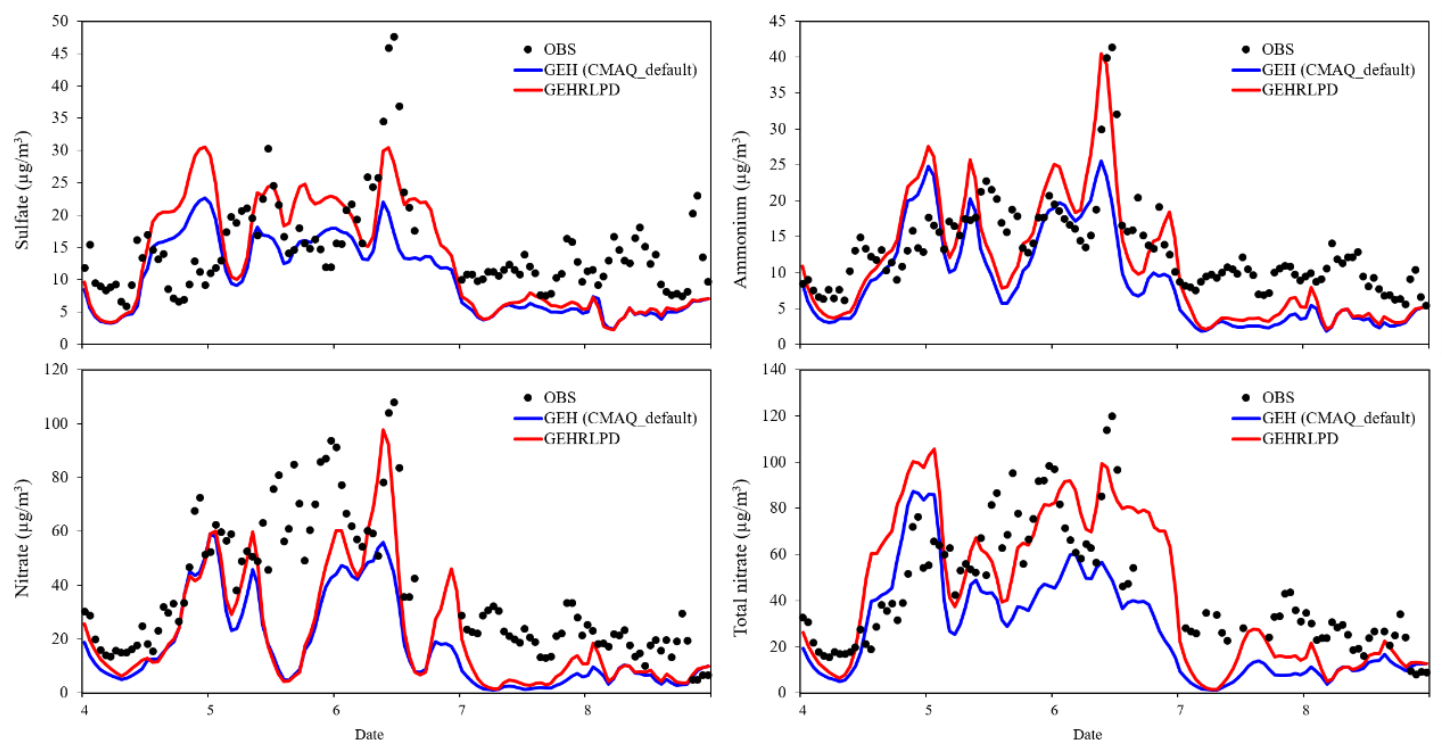

Fig. S3. Observed and simulated particle sulfate, ammonium, nitrate, and total nitrate concentrations by the default and revised CMAQ model at Heshan site 

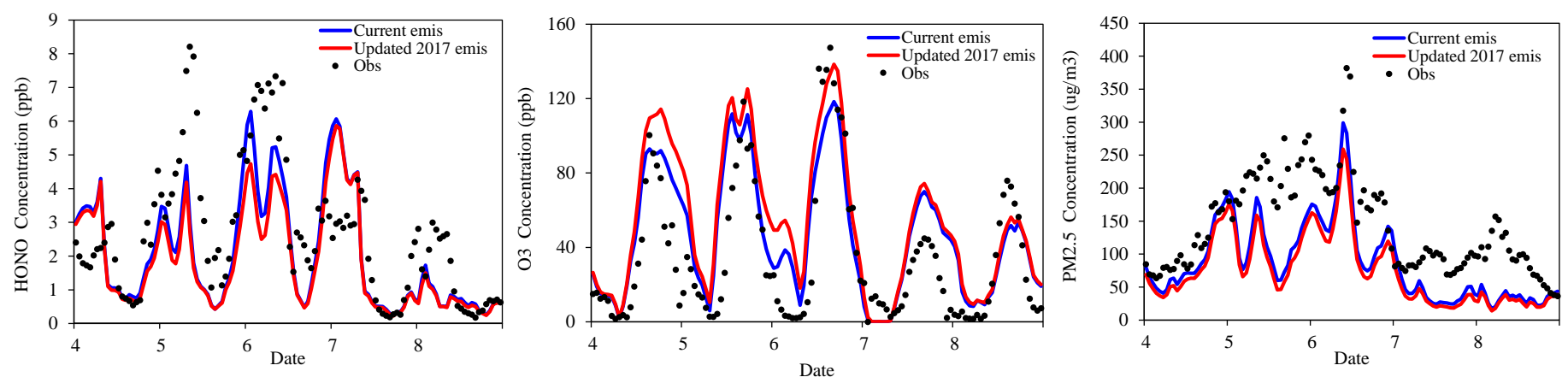

Fig. S4. Temporal variation of observed and simulated $\mathrm{HONO}, \mathrm{O}_{3}$, and $\mathrm{PM}_{2.5}$ concentrations with the current emissions and updated 2017 emissions. The updated 2017 emissions were obtained by linearly adjusting the current emissions based on the ratio of 2017 emission to 2010 emission for China reported in a very recent paper (Zheng et al., 2018)
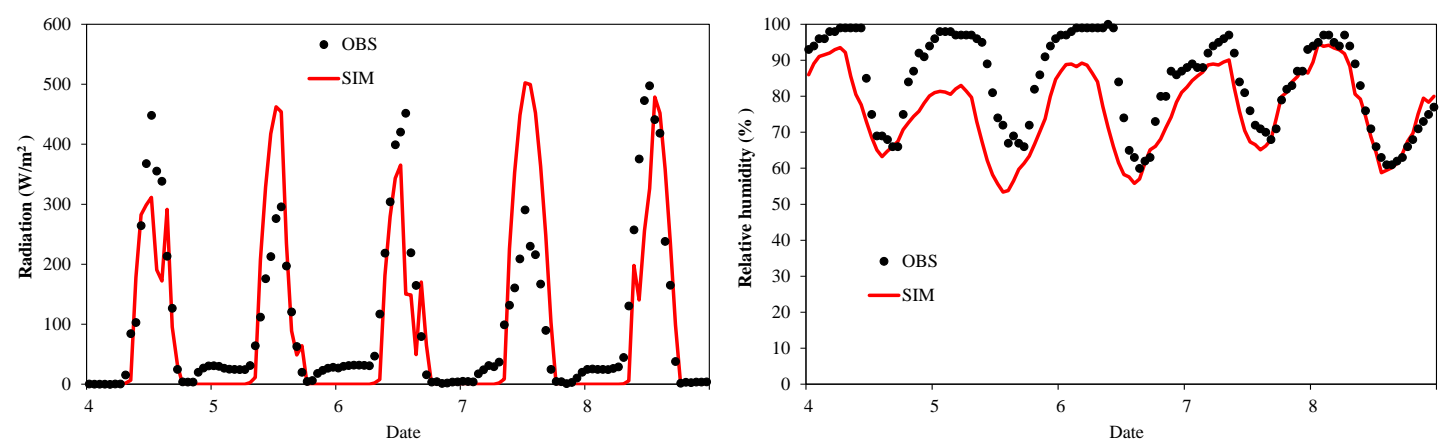

Fig. S5. Diurnal variations of observed and simulated radiation and relative humidity at Heshan site

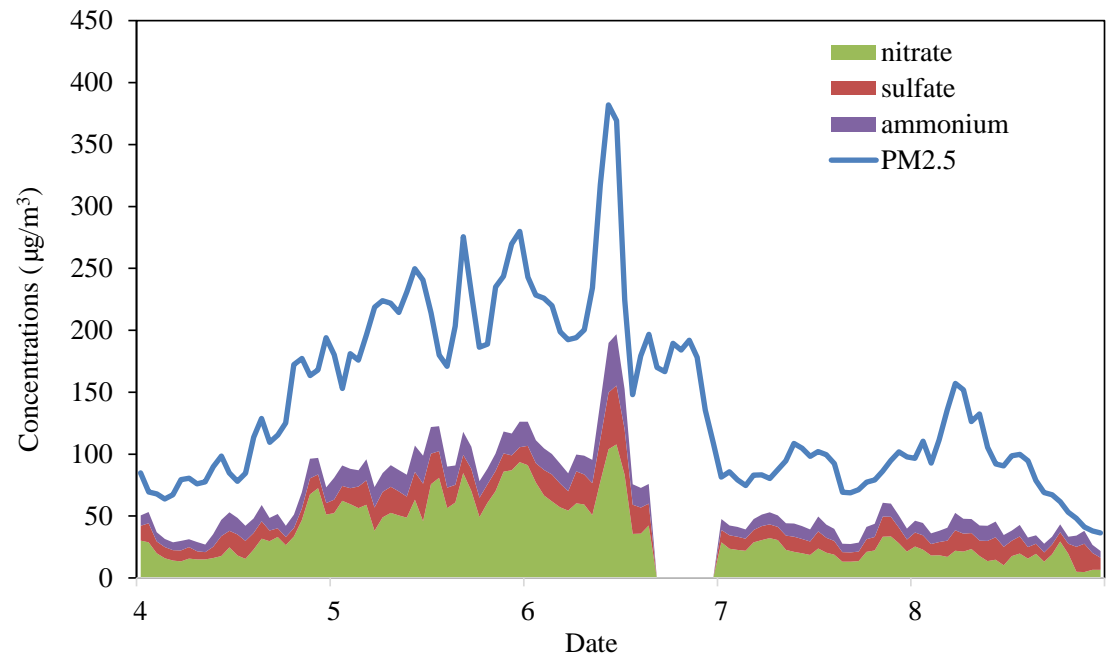

Fig. S6. Observed hourly variations of nitrate, sulfate, ammonium and $\mathrm{PM}_{2.5}$ concentrations during 4-8 January, 2017 at Heshan site. 


\section{References cited in this response:}

Zheng, B., Tong, D., Li, M., Liu, F., Hong, C., Geng, G., Li, H., Li, X., Peng, L., Qi, J., Yan, L., Zhang, Y., Zhao, H., Zheng, Y., He, K., and Zhang, Q.: Trends in China's anthropogenic emissions since 2010 as the consequence of clean air actions, Atmos. Chem. Phys., 18, 14095-14111, https://doi.org/10.5194/acp-18-14095-2018, 2018 